\title{
Open access journals in educational technology: Results of a survey of experienced users
}

\author{
Ross A. Perkins and Patrick R. Lowenthal \\ Boise State University
}

\begin{abstract}
As the academic publishing industry evolves, there has been an unprecedented growth of open access journals (OAJs). In educational technology alone, with an estimated 270 associated journals, nearly one-third are designated as open. Though OAJs are lauded for what their availability can contribute to social justice issues (reduction of subscription requirement barriers), some remain suspicious of the content found in them and question the legitimacy of publishing in them. In this study, we sought to discover the opinions of educational technology scholars about OAJs in their own field. We were able to learn which OAJs were deemed to be most valuable, as well as the characteristics of OAJs thought to be particularly important.
\end{abstract}

\section{Introduction}

Open access journals (OAJs), academic publications on the Internet free for anyone to read, have proliferated over the past several years (Björk et al., 2010; Khabsa \& Giles, 2014; Laakso et al., 2011; Van Noorden, 2013). Although some OAJs existed as early as the 1980s, the exponential increase in OAJs is correlated with the diffusion of the web and specifically with easy to use web-based publication management tools. The Directory of Open Access Journals (http://www.doaj.org) now lists more than 10,000 OAJs. Lewis (2012) argues that this growth will continue and predicts that over $50 \%$ of articles could be open access by 2021. Despite the growth of OAJs, many academics - even those researching and publishing scholarship in and related to educational technology, a field that in many ways embraces digital formats - struggle with whether or not to publish in OAJs (see Zwacki-Richter, Anderson, \& Tuncay, 2010). Given this, we set forth to investigate academics' perceptions of OAJs related to educational technology in hopes of identifying what makes a good OAJ.

\section{Review of literature}

During the past few years, OAJs have increased in popularity (see Anderson, 2013; Björk et al., 2010; Craig, Plume, McVeigh, Pringle, \& Amin, 2007; Veletsianos \& Kimmons, 2012; Zwacki-Richter et al., 2010). The increased popularity of OAJs is due to a number of reasons. First, many believe that research, some of which is publicly funded, should be free for the general public to access (Anderson, 2013; Oliver, 2012; Veletsianos \& Kimmons, 2012). Second, OAJs offer academics the possibility of a larger readership base (Anderson, 2013; Davis, 2011; Frass, Cross, \& Gardner, 2014; Swan \& Brown, 2004) by giving people all around the world (at least those with an Internet-connected device) access to one's work. Finally, some OAJs offer the opportunity to publish one's work faster than traditional journals (Frass et al., 2014; Swan \& Brown, 2004), which have been known to take months - if not at times years - to publish a manuscript.

Despite the purported benefits and strong supporters, many remain sceptical of OAJs (Agrawal, 2014; Bohanon, 2013; Lowenthal, 2015; Worlock, 2004). Most OAJs are relatively new - they neither have the history nor the marketing and branding expertise of traditional subscription-based journals. Many of them also lack a strong institutional affiliation. Much of the criticism of OAJs, though, revolves around a perceived lack of quality and the fees some OAJs charge. We will briefly address each of these in more detail.

A number of OAJs charge authors, or their institutions, to publish their work (Swan \& Brown, 2004). OAJs that charge publication fees argue that they are simply working from a different business model that passes on the cost to publish to authors instead of readers. Such fees, though, are anathema to academics who are accustomed to publishing their scholarship for free. The scepticism about fees to publish is further bolstered by a number of recent reports detailing sting operations in which academics intentionally submitted spurious works to OAJs - finding that their work could be published as soon as a publication fee is paid. 
Bohannon (2013), and the respected journal Science, set up such a sting operation to see how many OAJs would accept a manuscript with clear flaws. He submitted 304 versions of the paper over a 10-month period. By the time his article documenting the sting operation went to press, Bohannon (2013) noted that "more than half of the journals accepted the paper, failing to notice its fatal flaws" ( 13 ). The investigation was not a sweeping indictment of all OAJs. Bohannon pointed out that "some open-access journals that have been criticised for poor quality control provided the most rigorous peer review of all" ( 1 2). However, his research and others like it (Davis, 2009; Feltman, 2014a, 2014b; Stromberg, 2014) highlight the fact that poor and even predatory OAJs, whose main goal is to profit from publication fees, are readily found.

The criticism is both warranted and necessary. Just as there has been appropriate scrutiny leveled at forprofit education providers that have burdened students with debt but provided an education that is either not recognised or of low quality (Hensley-Clancy, 2014; Meszaros, 2014), there have been efforts to identify predatory OAJs so that scholars can avoid them (Beall, 2015). The problem, however, is that high-profile cases of predatory practices tend to stand out in much the same way that "diploma mill" stories stand out to critics of distance education (Contreras \& Golin, 2009). Not surprisingly, as the number of negative stories about pay-to-publish increases, many academics are beginning to question the quality of research that is published in any OAJ.

The desire and need to publish what is marked as quality research means that academics tend to seek outlets that stand up to closer scrutiny - particularly the quality of the peer-review process. As such, many academics, especially those seeking promotion and tenure or funding, tend to submit their work only to journals that have established quality indicators - the most common being the Institute for Scientific Information (ISI) impact factor. Although an in-depth discussion of the ISI impact factor is beyond the scope of this paper, it is important to note that despite its continued use, the ISI impact factor has been and continues to be criticised - especially when it is used as a sole metric for evaluating scholarship (see Hecht, Hecht, \& Sandberg, 1998; Smeyers \& Burbules, 2011; Togia \& Tsigilis, 2006; West \& Rich, 2012). The majority of journals with established quality indicators, like the ISI impact factor, tend to have a long reputable history but also require subscription fees that have become burdensome to libraries and that far exceed the ability of individuals to pay. Despite this, these long-standing journals with multiple quality indicators remain the most sought after journals to publish in. For instance, in educational technology, journals like Educational Technology Research and Development, the British Journal of Educational Technology, and Computers \& Education are still viewed by many as the most prestigious outlets in which to publish one's research (Ritzhaupt, Sessums, \& Johnson, 2012).

Academics find themselves confronted with a difficult decision to make. The increased popularity of OAJs, and the possible benefits these journals can bring, is likely to appeal to a growing number of academics; but academics must also consider the aforementioned criticisms or perceptions some hold of OAJs. But even once academics are open to the idea of publishing their work in an OAJ, they must be able to identify quality OAJs from low-quality or predatory ones. Identifying the best outlet to publish one's work - whether open access or not - has always been an important decision for academics (Ritzhaupt et al., 2012; West \& Rich, 2012). Unfortunately, there is little guidance for academics in educational technology to identify high-quality, influential OAJs in our field.

\section{Method}

Approximately one-third of journals in educational technology (or closely related to the field) are open access (see EdTech Journals., n.d; Rich \& West, 2012). The paucity of research on OAJs in the field of educational technology, however, leaves academics with scant information on how to choose a highquality OAJ when and if they choose to publish in one. We set forth to investigate what educational technology professionals - specifically those with OAJ experience - think about OAJs in our field. More specifically, we were interested in answering the following questions:

- Which OAJs related to educational technology do professionals in the field see as the most influential?

- Which characteristics of OAJs do educational technology professionals see as the most useful? 


\section{Instrument}

We created a web-based survey with two parts. The first part of the survey had 20 questions focusing on academic publishing and characteristics of OAJs, as well as a few general questions about demographics of the participants. Those who completed the first part of the survey could then choose to complete the second part of the survey, but could end after Part 1 if they so desired. The second part of the survey consisted of 12 additional questions that we thought were important but not critical to our inquiry.

\section{Sample}

For our study, we solicited feedback from two different groups of scholars. We began our inquiry focused on academics who have published in OAJs in the past. From 26 OAJs related to educational technology, we identified 1,200 open-access articles written by 2,208 authors. We sent the survey to 2,081 scholars with valid email addresses, 362 (16.4\%) of whom accessed the survey. Of these 362 initial respondents, 236 completed Part 1 (11.3\% of those solicited). In this article, we only focus on Part 1 responses, as Part 2 contained questions outside the scope of our main research questions; results from Part 2 will be reported separately. We will refer to this sample of OAJ authors as Sample 1 (SM1).

While we were collecting data from SM1, we thought it would be useful to make the survey available to other educational technology professionals via listservs and social media (including a larger possible audience of both those who have and have not published in OAJs in the past). Response rates (percentages) are not available for this second sample, which we will refer to as Sample 2 (SM2). For SM2, a total of 196 people accessed the survey, 157 of whom completed Part 1.

Overall when combining SM1 and SM2, a total of 558 people accessed the survey, and 393 completed Part 1. Among those who completed Part 1, a total of 323 of the respondents had previous experience with OAJs. Hereafter, we do not include the responses of 67 participants from SM2 who lacked previous experience with OAJs.

Table 1

Survey response counts and rates

\begin{tabular}{llll}
\hline Action & Sample 1 (SM1) & Sample 2 (SM2) & Total \\
\hline Solicited & 2,208 & number unknown & $>2,208$ \\
Valid emails & 2,081 & n/a & 2,081 \\
Opened survey & $362(16.4 \%)$ & 196 & 558 \\
Completed Part 1 & $236(11.3 \%)$ & $157(80.1 \%$ of 196$)$ & 393 \\
Met criteria, Part 1 & $233(11.2 \%)$ & $90(57.3 \%$ of 157$)$ & 323 \\
\hline
\end{tabular}

\section{Demographics}

The demographic data from Part 1 of the survey for SM1 and SM2 are discussed in the following section. We first asked participants to select from a list of 26 geographic regions, up to four regions (e.g., Asia: South; Europe: Northern; and Oceania: Polynesia) that had a profound influence on their personal or professional lives (see Table 2). An independent sample $t$-test of the mean number of regions chosen by each group $(\mathrm{SM} 1=1.66, \mathrm{SM} 2=1.47)$ indicates a significant difference between the two samples with respect to geographic diversity $(t(240)=2.11, p<.05)$.

Table 2

Geographic regions of influence

\begin{tabular}{lcccc}
\hline & $\begin{array}{c}\text { Sample } 1(n= \\
233)\end{array}$ & $\begin{array}{c}\text { \% of total } \\
\text { indicated }\end{array}$ & Sample 2 $(n=90)$ & $\begin{array}{c}\text { \% of total } \\
\text { indicated }\end{array}$ \\
\hline Africa & 13 & $3.29 \%$ & 6 & $4.69 \%$ \\
Americas & 135 & $34.18 \%$ & 83 & $64.84 \%$ \\
Asia & 74 & $18.73 \%$ & 15 & $11.72 \%$ \\
Europe & 130 & $32.91 \%$ & 17 & $13.28 \%$ \\
Oceania & 42 & $10.63 \%$ & 2 & $1.56 \%$ \\
\hline Totals & 395 & & 128 & \\
\hline Mean regions selected & 1.66 & & 1.47 & \\
\hline
\end{tabular}


The demographic data revealed that SM1 (i.e., the open journal authors group) participants had predominantly European and Australian/New Zealander influences whereas SM2 participants had predominantly a North American influence. Such a large difference between the groups warranted closer consideration. When looking at the demographic data of SM1 and SM2 combined, we found 157 (48\%) of participants were predominantly North American (PNAM) versus 167 (52\%) of participants that were predominantly international (INTL). The PNAM and INTL groups are very similar on the other demographic indicators (i.e., chi-square tests show no significant differences). We therefore report data from this point forward based on these two groups rather than by SM1 or SM2.

We then asked participants about their years of experience in the field as well as their professional field and title. The PNAM group $(n=154)$ had an average of 11.1 years $(S D=8.72)$ in the field whereas the INTL group $(n=166)$ had an average of 13.2 years $(S D=8.52)$ in the field. Approximately $52 \%$ of the INTL group and $48 \%$ of the PNAM group reported working in educational technology or a closely related field. With respect to professional title, $67 \%$ of INTL group and $68 \%$ of the PNAM group listed their title as professor, lecturer, or instructor. The PNAM group had slightly more instructional designers, as well as managers and directors, and the INTL group had a few more post-doctoral or research professionals, but the groups have nearly an identical make-up otherwise.

Finally, we asked some specific questions about each participant's experience with OAJs:

- How many publications have you had since 2010?

- How many times have you published in Open Access Journals since 2010?

- What experience have you had working with OAJs?

Tables 3 and 4 show that $41 \%$ of the INTL group and $36 \%$ of the PNAM group have published six or more articles since $2010 ; 11 \%$ of INTL and 7\% of PNAM reported publishing six or more articles in OAJs. We also asked about other ways that participants might be involved with OAJs. Table 5 shows that most participants are authors and/or occasional reviewers.

Table 3

Published any article since 2010

\begin{tabular}{lcccc}
\hline Articles published & $\begin{array}{c}\text { INTL } \\
(n=167)\end{array}$ & $\%$ of total & $\begin{array}{c}\text { PNAM } \\
(n=157)\end{array}$ & \% of total \\
\hline None & 1 & $0.60 \%$ & 9 & $5.77 \%$ \\
$1-2$ & 26 & $15.57 \%$ & 29 & $18.59 \%$ \\
$2-3$ & 39 & $23.35 \%$ & 35 & $22.44 \%$ \\
$4-5$ & 32 & $19.16 \%$ & 27 & $17.31 \%$ \\
6 or more & 69 & $41.32 \%$ & 56 & $35.90 \%$ \\
\hline
\end{tabular}

Table 4

Articles in an open access journal since 2010

\begin{tabular}{lcccc}
\hline Articles published & $\begin{array}{c}\text { INTL } \\
(n=163)\end{array}$ & $\%$ of total & $\begin{array}{c}\text { PNAM } \\
(n=145)\end{array}$ & $\%$ of total \\
\hline None & 7 & $4.29 \%$ & 19 & $13.10 \%$ \\
$1-2$ & 94 & $57.67 \%$ & 82 & $56.55 \%$ \\
$2-3$ & 30 & $18.40 \%$ & 22 & $15.17 \%$ \\
$4-5$ & 14 & $8.59 \%$ & 12 & $8.28 \%$ \\
6 or more & 18 & $11.04 \%$ & 10 & $6.90 \%$ \\
\hline
\end{tabular}


Table 5

Roles or positions with OAJs

\begin{tabular}{lcccc}
\hline Role or position & $\begin{array}{c}\text { INTL } \\
(n=163)\end{array}$ & $\begin{array}{c}\text { \% of total } \\
\text { indicators }\end{array}$ & $\begin{array}{c}\text { PNAM } \\
(n=145)\end{array}$ & $\begin{array}{c}\text { \% of total } \\
\text { indicators }\end{array}$ \\
\hline Main editor & 28 & $8.24 \%$ & 20 & $6.90 \%$ \\
Editorial board & 37 & $10.88 \%$ & 28 & $9.66 \%$ \\
Frequent reviewer & 42 & $12.35 \%$ & 30 & $10.34 \%$ \\
Occasional reviewer & 68 & $20.00 \%$ & 69 & $23.79 \%$ \\
Regular contributor & 21 & $6.18 \%$ & 14 & $4.83 \%$ \\
Author or co-author & 143 & $42.06 \%$ & 124 & $42.76 \%$ \\
None & 1 & $0.29 \%$ & 5 & $1.72 \%$ \\
\hline Total & 340 & & 290 & \\
\hline
\end{tabular}

\section{Results}

We now describe the results from Part 1 of the survey. The results will be presented using the aforementioned regional groups, those who have only North American or primarily North American influences (PNAM), and those who have no North American influence, or have a more diverse mix of regional influences (INTL).

\section{Top 5 most influential journals}

We were interested in finding out which $\mathrm{OAJ}_{\mathrm{S}}$ academics thought were most influential in the field of educational technology. Therefore, we asked participants to select five OAJs that they thought were influential. Participants were given five identical questions that asked them to select an OAJ that they thought was influential from a drop-down menu listing 80 OAJs. The list of OAJs was initially found by examining the contents of a shared spreadsheet that was the result of a collaboration of professionals in educational technology. The titles found on that spreadsheet were then compared to entries found in popular directories of academic journals (e.g., Directory of Open Access Journals, Cabell's Directory of Publishing Opportunities, and Ulrich's Periodicals Directory), the result of which yielded categorising descriptors or keywords. Researchers then used keywords such as educational (or instructional) technology, distance education, computer-based education, electronic learning, and so on to search the directories for all journals so categorised. OAJs in education or related fields that may publish pertinent articles, but which primarily focus on teaching and learning without a technology focus, were excluded given our specific focus. Any OAJs found to be shuttered were excluded (e.g., Innovate: Journal of Online Education). After several iterations and an informal review by colleagues, the list of OAJs was thought to be as exhaustive as the researchers felt it could be at the time. Given the speed at which new OAJs can be created, and as some exist outside of popular directories, the list of 80 would have to be appended in a future study. The journals were listed in alphabetical order; participants saw approximately the first 12 journals before having to scroll down to find others. Each participant could select up to five journals that $\mathrm{s} /$ he considered influential. The average participant selected about four influential journals (see Table 6). More specifically, participants in the INTL group selected $4.01(S D=1.50)$ influential OAJs, whereas participants in the PNAM group selected $3.73(S D=1.46)$ influential OAJs. An independent sample $t$-test shows no significant difference between the means.

Table 6

Comparison of total votes for each possible journal slot

\begin{tabular}{lcccc}
\hline Status & INTL & $\%$ of total & PNAM & $\%$ of total \\
\hline Influential OAJ 1 & 167 & $100.0 \%$ & 156 & $100.0 \%$ \\
Influential OAJ 2 & 147 & $88.0 \%$ & 140 & $89.7 \%$ \\
Influential OAJ 3 & 127 & $76.1 \%$ & 115 & $73.7 \%$ \\
Influential OAJ 4 & 117 & $70.1 \%$ & 92 & $60.0 \%$ \\
Influential OAJ 5 & 112 & $67.1 \%$ & 80 & $51.3 \%$ \\
\hline
\end{tabular}

Not being selected as an influential journal does not mean that a journal is low quality. It could simply mean that the journal is new and not recognisable by academics. Therefore, we avoided ranking all 80 OAJs. Instead, we identified all journals that received at least 10 votes by participants, separated by INTL 
and PNAM. The following were selected as influential OAJs most commonly across both groups: EDUCAUSE Quarterly / Review, the Australasian Journal of Educational Technology, International Review of Research in Open and Distance Learning, Educational Technology \& Society, and First Monday. Table 7 shows a full listing of all educational technology journals receiving at least 10 votes.

Interestingly, the PNAM and INTL groups differed in which OAJs they selected as influential. For instance, the PNAM group listed EDUCAUSE Quarterly / Review, International Review of Research in Open and Distance Learning, and First Monday the most frequently. The INTL group, on the other hand, listed Australasian Journal of Educational Technology, EDUCAUSE Quarterly / Review, and Educational Technology \& Society the most frequently.

Table 7

Votes and ranking: Top 5 OAJs

\begin{tabular}{|c|c|c|c|c|c|}
\hline OAJ title & $\begin{array}{l}\text { Listed in top } \\
\qquad 5\end{array}$ & $\begin{array}{l}\text { Mean of \% } \\
\text { of votes }\end{array}$ & $\begin{array}{l}\text { INTL } \\
\text { rank }\end{array}$ & $\begin{array}{l}\text { PNAM } \\
\text { rank }\end{array}$ & $\begin{array}{c}\text { Rank } \\
\text { difference }\end{array}$ \\
\hline $\begin{array}{l}\text { EDUCAUSE Quarterly / Review } \\
\text { (EDUCAUSE) }\end{array}$ & Both & $10.33 \%$ & 2 & 1 & 1 \\
\hline $\begin{array}{l}\text { Australasian Journal of Educational } \\
\text { Technology (AJET) }\end{array}$ & Both & $6.60 \%$ & 1 & 8 & 7 \\
\hline $\begin{array}{l}\text { International Review of Research in Open } \\
\text { and Distributed Learning (IRRODL) }\end{array}$ & Both & $6.30 \%$ & 5 & 2 & 3 \\
\hline Educational Technology \& Society (ETS) & Both & $5.96 \%$ & 3 & 6 & 3 \\
\hline First Monday & Both & $5.36 \%$ & 6 & 3 & 3 \\
\hline $\begin{array}{l}\text { Contemporary Issues in Technology and } \\
\text { Teacher Education (CITE Journal) }\end{array}$ & Both & $4.67 \%$ & 6 & 5 & 1 \\
\hline $\begin{array}{l}\text { European Journal of Open and Distance } \\
\text { Learning (EURODL) }\end{array}$ & Both & $4.42 \%$ & 4 & 11 & 7 \\
\hline $\begin{array}{l}\text { Journal of Online Learning and Teaching } \\
\text { (JOLT) }\end{array}$ & Both & $4.30 \%$ & 9 & 4 & 5 \\
\hline $\begin{array}{l}\text { Canadian Journal of Learning and } \\
\text { Technology (CJLT) }\end{array}$ & Both & $3.79 \%$ & 7 & 7 & 0 \\
\hline Journal of Distance Education (JDE) & Both & $3.07 \%$ & 8 & 9 & 1 \\
\hline $\begin{array}{l}\text { Journal of Asynchronous Learning } \\
\text { Networks (JALN) }\end{array}$ & Both & $2.35 \%$ & 11 & 10 & 1 \\
\hline Electronic Journal of e-Learning (EJEL) & Both & $2.30 \%$ & 8 & 13 & 5 \\
\hline $\begin{array}{l}\text { Online Journal of Distance Learning } \\
\text { Administration (OJDLA) }\end{array}$ & Both & $1.94 \%$ & 12 & 12 & 0 \\
\hline $\begin{array}{l}\text { International Journal of Educational } \\
\text { Research and Technology (IJERT) }\end{array}$ & Both & $1.86 \%$ & 13 & 12 & 1 \\
\hline $\begin{array}{l}\text { THE Journal: Transforming Education } \\
\text { through Technology (THE Journal) }\end{array}$ & PNAM & $1.81 \%$ & 16 & 11 & 5 \\
\hline $\begin{array}{l}\text { Journal of Computer-Mediated } \\
\text { Communication (JCMC) }\end{array}$ & Both & $1.69 \%$ & 13 & 14 & 1 \\
\hline $\begin{array}{l}\text { Turkish Online Journal of Distance } \\
\text { Education (TOJDE) }\end{array}$ & INTL & $1.53 \%$ & 8 & 21 & 13 \\
\hline Journal of Technology Education (JTE) & PNAM & $1.31 \%$ & 17 & 15 & 2 \\
\hline $\begin{array}{l}\text { Turkish Online Journal of Educational } \\
\text { Technology (TOJET) }\end{array}$ & INTL & $1.22 \%$ & 9 & 22 & 13 \\
\hline eLearning Papers (eL Papers) & INTL & $1.07 \%$ & 11 & 22 & 11 \\
\hline Research in Learning Technology (ALT-J) & INTL & $1.06 \%$ & 10 & 23 & 13 \\
\hline Kairos & PNAM & $1.03 \%$ & 23 & 13 & 10 \\
\hline $\begin{array}{l}\text { International Journal of Designs for } \\
\text { Learning (IJDL) }\end{array}$ & PNAM & $1.02 \%$ & 22 & 14 & 8 \\
\hline
\end{tabular}




\section{Characteristic of journals}

Recognising that OAJs can wax and wane in their influence, we were interested in identifying important characteristics of any scholarly journal and then specifically important characteristics of OAJs. Therefore, we first asked participants to indicate how important nine different characteristics were for any journal on a scale ranging from important (1), to neither important nor unimportant (2) and unimportant (3). Across both groups, academics reported that scope and purpose and being peer reviewed and abstracted are important characteristics of any journal (see Table 8). Using independent sample $t$-tests to examine the mean score differences between the INTL and PNAM group, some significant differences appear, as indicated in Table 8. More specifically, the INTL group rated the importance of whether a journal is abstracted or has an impact factor higher than the PNAM group.

Table 8

Importance of characteristics of any journal

\begin{tabular}{|c|c|c|c|c|c|c|c|}
\hline \multirow[b]{2}{*}{ Characteristic } & \multirow[b]{2}{*}{ Overall mean } & \multicolumn{3}{|c|}{ INTL } & \multicolumn{3}{|c|}{ PNAM } \\
\hline & & $n$ & $M$ & $S D$ & $n$ & $M$ & $S D$ \\
\hline Peer reviewed refereed & 1.050 & 166 & 1.05 & 0.22 & 155 & 1.05 & 0.24 \\
\hline Journal scope or purpose & 1.075 & 165 & 1.08 & 0.31 & 155 & 1.07 & 0.26 \\
\hline Abstracted* & 1.195 & 166 & 1.13 & 0.41 & 156 & 1.26 & 0.52 \\
\hline Speed of review/publication & 1.280 & 165 & 1.27 & 0.5 & 156 & 1.29 & 0.48 \\
\hline Impact factor of the journal* & 1.350 & 166 & 1.26 & 0.48 & 153 & 1.44 & 0.63 \\
\hline Number of readers & 1.355 & 166 & 1.34 & 0.54 & 153 & 1.37 & 0.56 \\
\hline Open access & 1.465 & 165 & 1.46 & 0.66 & 154 & 1.47 & 0.59 \\
\hline Manuscript acceptance rate & 1.565 & 162 & 1.57 & 0.65 & 154 & 1.56 & 0.64 \\
\hline Pay to publish & 1.880 & 161 & 1.81 & 0.82 & 153 & 1.91 & 0.85 \\
\hline
\end{tabular}

* Mann-Whitney U test, $p<.05$

We then asked participants to rate 15 factors that may impact the perceived prestige and trustworthiness of any OAJ on a scale ranging from highly desirable (1), through somewhat desirable (2), to not important/not desirable (3), or they could choose no opinion. Across both groups, the three most important characteristics of an OAJ are that it is listed in indexing/abstracting databases, articles are frequently cited by others, and that it has a consistent record of publications over time (see Table 9). However, the INTL and PNAM groups placed different importance on certain characteristics. For instance, the INTL group listed found in indexing/abstracting databases, frequently cited by others, and no publication fee the most frequently, whereas the PNAM group listed consistent record of publications, found in indexing/abstracting databases, and no publication fee the most frequently. Statistical differences between the two groups were found for 11 of the 15 items (see Table 9). 
Table 9

Characteristics important to OAJs

\begin{tabular}{|c|c|c|c|c|c|c|c|c|}
\hline \multirow[b]{2}{*}{ Characteristic } & \multirow{2}{*}{$\begin{array}{l}\text { Overall } \\
\text { mean }\end{array}$} & \multirow{2}{*}{$\begin{array}{l}\text { Between } \\
\text { groups } \\
\text { sig. }\end{array}$} & \multicolumn{3}{|c|}{ INTL } & \multicolumn{3}{|c|}{ PNAM } \\
\hline & & & $n$ & $M$ & $S D$ & $n$ & $M$ & $S D$ \\
\hline $\begin{array}{l}\text { Found in } \\
\text { indexing/abstracting } \\
\text { databases } * *\end{array}$ & 1.330 & 0.023 & 154 & 1.25 & 0.46 & 154 & 1.41 & 0.62 \\
\hline $\begin{array}{l}\text { Frequently cited by other } \\
\text { authors } * * *\end{array}$ & 1.365 & 0.007 & 153 & 1.28 & 0.48 & 153 & 1.45 & 0.57 \\
\hline $\begin{array}{l}\text { Consistent record of } \\
\text { publications over a period } \\
\text { of time*** }\end{array}$ & 1.370 & 0.002 & 155 & 1.44 & 0.35 & 155 & 1.3 & 0.49 \\
\hline $\begin{array}{l}\text { No publication fee is } \\
\text { required }\end{array}$ & 1.375 & 0.246 & 147 & 1.33 & 0.62 & 147 & 1.42 & 0.69 \\
\hline $\begin{array}{l}\text { Has a high readership or } \\
\text { membership base* }\end{array}$ & 1.480 & 0.069 & 153 & 1.42 & 0.6 & 153 & 1.54 & 0.62 \\
\hline $\begin{array}{l}\text { Has recognisable scholars } \\
\text { on editorial board }\end{array}$ & 1.480 & 0.300 & 154 & 1.44 & 0.61 & 154 & 1.52 & 0.65 \\
\hline $\begin{array}{l}\text { Affiliation with a } \\
\text { professional organisation or } \\
\text { university }\end{array}$ & 1.485 & 0.364 & 154 & 1.52 & 0.65 & 154 & 1.45 & 0.59 \\
\hline $\begin{array}{l}\text { Has a professional looking } \\
\text { website }\end{array}$ & 1.530 & 0.952 & 155 & 1.53 & 0.65 & 155 & 1.53 & 0.65 \\
\hline $\begin{array}{l}\text { In the Social Science } \\
\text { Citation Index**** }\end{array}$ & 1.680 & 0.000 & 139 & 1.51 & 0.65 & 139 & 1.85 & 0.75 \\
\hline $\begin{array}{l}\text { In the Directory of Open } \\
\text { Access Journals (DOAJ)* }\end{array}$ & 1.865 & 0.072 & 136 & 1.78 & 0.73 & 136 & 1.95 & 0.77 \\
\hline $\begin{array}{l}\text { In Ulrich's Periodicals } \\
\text { Directory**** }\end{array}$ & 2.165 & 0.000 & 124 & 1.99 & 0.73 & 124 & 2.34 & 0.72 \\
\hline $\begin{array}{l}\text { In Cabell's Directory of } \\
\text { Publishing } \\
\text { Opportunities } * * *\end{array}$ & 2.185 & 0.008 & 123 & 2.07 & 0.73 & 123 & 2.3 & 0.79 \\
\hline $\begin{array}{l}\text { Publishes high volume of } \\
\text { articles each year**** }\end{array}$ & 2.325 & 0.000 & 149 & 2.15 & 0.77 & 149 & 2.5 & 0.65 \\
\hline $\begin{array}{l}\text { Print edition that } \\
\text { accompanies an electronic } \\
\text { edition }\end{array}$ & 2.555 & 0.693 & 153 & 2.56 & 0.69 & 153 & 2.55 & 0.65 \\
\hline $\begin{array}{l}\text { Publishes relatively few } \\
\text { articles each year** }\end{array}$ & 2.560 & 0.021 & 143 & 2.46 & 0.7 & 143 & 2.66 & 0.55 \\
\hline $\begin{array}{l}\text { Requires authors to pay a } \\
\text { fee in order to publish*** }\end{array}$ & 2.845 & 0.010 & 126 & 2.77 & 0.56 & 126 & 2.92 & 0.36 \\
\hline $\begin{array}{l}*<.10 \\
* *<.05 \\
* * *<=.01 \\
* * * *<.001\end{array}$ & & & & & & & & \\
\hline
\end{tabular}

\section{Publishing choices and experiences}

The discourse surrounding OAJs can be polemical. Often we only hear the views of some of the most vocal supporters and critics of OAJs. From the outset of our inquiry, in addition to identifying influential educational technology OAJs, we were interested in why academics publish in OAJs and their overall experiences with these journals. Thus, we asked participants whether OAJs are usually their first choice of a place to publish, how they would rate the quality of peer review of these journals, and how likely they are to submit another manuscript to an OAJ within the next 18 months. Across both groups, the majority of participants $(66.70 \%$ to $70.50 \%)$ listed that their choice of publishing in an OAJ depends on the content. However, a quarter to a fifth of each group did report that OAJs are their first choice of 
publication. Then when asked about their review experiences, over $65 \%$ of participants in both groups reported that the reviews were consistently good or consistently excellent. Finally, when asked how likely they are to submit another manuscript to OAJ in the next 18 months, $76.5 \%$ of INTL and $68 \%$ of the PNAM reported that they are highly likely to do so or definitely will do so. We then used a chi-square analysis to look for any statistical differences between the groups for these three questions, but none was found.

Table 10

Choice of $O A J$

\begin{tabular}{lcc}
\hline Response & INTL & PNAM \\
First choice & $(n=165)$ & $(n=156)$ \\
Next choice & $23.60 \%$ & $20.50 \%$ \\
Depends on content & $3.60 \%$ & $3.80 \%$ \\
Depends on speed & $66.70 \%$ & $70.50 \%$ \\
\hline
\end{tabular}

Table 11

Review experiences

\begin{tabular}{|c|c|c|}
\hline Response & $\begin{array}{c}\text { INTL } \\
(n=164)\end{array}$ & $\begin{array}{c}\text { PNAM } \\
(n=154)\end{array}$ \\
\hline Consistently excellent & $12.20 \%$ & $15.60 \%$ \\
\hline Consistently good & $54.90 \%$ & $51.30 \%$ \\
\hline Consistently mediocre & $11.60 \%$ & $7.10 \%$ \\
\hline Consistently poor & $1.20 \%$ & $1.30 \%$ \\
\hline Inconsistently good & $15.90 \%$ & $14.30 \%$ \\
\hline Inconsistently poor & $2.40 \%$ & $3.90 \%$ \\
\hline Not applicable & $1.80 \%$ & $6.50 \%$ \\
\hline
\end{tabular}

Table 12

Likelihood of submitting to OAJ in 18 months

\begin{tabular}{|c|c|c|}
\hline Response & $\begin{array}{c}\text { INTL } \\
(n=166)\end{array}$ & $\begin{array}{c}\text { PNAM } \\
(n=156)\end{array}$ \\
\hline Definitely & $33.70 \%$ & $35.30 \%$ \\
\hline Highly likely & $42.80 \%$ & $32.70 \%$ \\
\hline Somewhat likely & $19.90 \%$ & $28.20 \%$ \\
\hline Unlikely & $3.60 \%$ & $3.80 \%$ \\
\hline No intention & $0.00 \%$ & $0.00 \%$ \\
\hline
\end{tabular}

\section{Experience with most influential journals}

We were also interested in learning more about the experiences academics had with the OAJs they listed as most influential. Using the journals participants previously identified as the most influential, we asked participants a series of follow-up questions on those selected journals. Across both groups 194 (48\%) had published in, $85(21 \%)$ had reviewed for, and $24(6 \%)$ had served in an editorial role for the first influential journal that they identified from the list of 80 OAJs. At the same time, though, a large percentage of participants had no direct experience with journals they selected (see Table 13). 
Table 13

Experience with OAJs selected as influential

\begin{tabular}{ccccc}
\hline & Published in & Reviewed for & Editorial function & $\begin{array}{c}\text { No direct } \\
\text { experience }\end{array}$ \\
\hline Journal 1 & $48 \%$ & $21 \%$ & $6 \%$ & $25 \%$ \\
INTL & 114 & 45 & 16 & 42 \\
PNAM & 80 & 40 & 8 & 60 \\
Journal 2 & $26 \%$ & $16 \%$ & $4 \%$ & $54 \%$ \\
INTL & 39 & 25 & 6 & 95 \\
PNAM & 44 & 26 & 6 & 78 \\
Journal 3 & $16 \%$ & $9 \%$ & $2 \%$ & $73 \%$ \\
INTL & 18 & 15 & 5 & 95 \\
PNAM & 21 & $10 \%$ & 0 & 86 \\
Journal 4 & $14 \%$ & 13 & $3 \%$ & $73 \%$ \\
INTL & 12 & 9 & 6 & 89 \\
PNAM & 17 & $7 \%$ & 0 & 66 \\
Journal 5 & $11 \%$ & 8 & $4 \%$ & $78 \%$ \\
INTL & 11 & 6 & 5 & 88 \\
PNAM & 10 & & 2 & 61 \\
\hline
\end{tabular}

In addition, we were interested in learning more about what participants know about the OAJs that they find influential. For instance, we wondered if those who publish in OAJs might spend more time reading and citing articles in OAJs. Thus, we asked participants how often they read, cite, or recommend articles from these influential OAJs - in which $49 \%$ responded that they regularly or frequently read, cite, or comment on OAJs (see Figure 1).

Some have suggested that one benefit of OAJs is that they can speed up the review process. But when asked directly about their perception or knowledge of the speed of the editorial review process, $49 \%$ reported that they did not know, and only $9 \%$ reported that it was very fast (see Figure 1).

We then inquired about participants' perceptions of the editorial review process for these influential journals. Although $51 \%$ reported that they believed the editorial review process was rigorous or very rigorous, $43 \%$ revealed that they did not know.

Finally, we asked about participants' knowledge of the rate of acceptance. There is a long-standing tradition in academia of seeing a low acceptance rate as a sign of journal quality. And while $29 \%$ believed these influential OAJs had an average rate of acceptance, only $9 \%$ reported that they had a low acceptance rate, and 57\% reported that they did not know (see Table 14).

Table 14

Experience with most influential OAJs

\begin{tabular}{lcccc}
\hline Read/cite/comment on OAJs & Frequently & Regularly & Occasionally & Rarely \\
& $17 \%$ & $32 \%$ & $37 \%$ & $14 \%$ \\
\hline Speed of review process & Very fast & Expected & Slower & Unknown \\
& $9 \%$ & $33 \%$ & $9 \%$ & $49 \%$ \\
\hline Rate of article acceptance & Low & Average & High & Unknown \\
& $9 \%$ & $29 \%$ & $5 \%$ & $57 \%$ \\
\hline Rigor of peer review process & Very rigorous & Rigorous & Not as rigorous & Unknown \\
& $14 \%$ & $37 \%$ & $6 \%$ & $43 \%$ \\
\hline Prestige of OAJs & More & As prestigious & Less & Prefer not to \\
& prestigious & & prestigious & answer \\
& $14 \%$ & $53 \%$ & $23 \%$ & $10 \%$ \\
\hline
\end{tabular}

In addition to learning more about what participants knew about these influential journals, we were interested in finding out whether they saw these influential OAJs as comparable to other top journals in our field. Therefore, we specifically asked participants to compare the OAJs that they had previously identified as influential to other top journals in our field on a scale ranging from (1) more prestigious, (2) as prestigious, and (3) less prestigious, to (4) prefer not to answer. Across both groups, over $67 \%$ viewed 
the OAJs that they had previously identified as influential as being as prestigious or more prestigious than other top journals in our field. However, 23\% reported that they view the influential OAJs as less prestigious than other top journals in our field, and almost $10 \%$ stated that they prefer not to answer this question.

In Table 15 we present many of the same 25 journals as appeared in Table 7, but in a different order.

Table 15

Comparison of important characteristics of top 5 selected journals (ranked by mean of all characteristics)

\begin{tabular}{|c|c|c|c|c|c|c|}
\hline Journal name & M & Prestige & Interaction & Speed & RoA & Rigor \\
\hline $\begin{array}{l}\text { Research in Learning Technology (ALT- } \\
J)\end{array}$ & 1.753 & 1.917 & 2.017 & 1.917 & 1.625 & 1.292 \\
\hline Kairos & 1.843 & 1.833 & 2.356 & 2.250 & 1.333 & 1.444 \\
\hline $\begin{array}{l}\text { Online Journal of Distance Learning } \\
\text { Administration (OJDLA) }\end{array}$ & 1.967 & 1.822 & 2.089 & 1.853 & 2.290 & 1.778 \\
\hline $\begin{array}{l}\text { Australasian Journal of Educational } \\
\text { Technology (AJET) }\end{array}$ & 1.989 & 1.948 & 2.493 & 2.081 & 1.718 & 1.704 \\
\hline eLearning Papers (eL Papers) & 1.990 & 2.000 & 2.400 & 1.800 & 1.875 & 1.875 \\
\hline $\begin{array}{l}\text { Journal of Asynchronous Learning } \\
\text { Networks (JALN) }\end{array}$ & 1.994 & 1.970 & 2.232 & 1.933 & 1.833 & 2.000 \\
\hline $\begin{array}{l}\text { Educational Technology \& Society } \\
\text { (ETS) }\end{array}$ & 1.998 & 1.890 & 2.389 & 2.292 & 1.656 & 1.764 \\
\hline $\begin{array}{l}\text { Journal of Computer-Mediated } \\
\text { Communication (JCMC) }\end{array}$ & 2.003 & 2.017 & 2.417 & 2.333 & 1.556 & 1.690 \\
\hline First Monday & 2.007 & 2.064 & 2.316 & 1.914 & 1.923 & 1.818 \\
\hline $\begin{array}{l}\text { International Journal of Designs for } \\
\text { Learning (IJDL) }\end{array}$ & 2.033 & 2.000 & 2.533 & 1.833 & 2.000 & 1.800 \\
\hline $\begin{array}{l}\text { EDUCAUSE Quarterly / Review } \\
\text { (EDUCAUSE) }\end{array}$ & 2.042 & 2.061 & 2.569 & 1.842 & 1.863 & 1.876 \\
\hline $\begin{array}{l}\text { Canadian Journal of Learning and } \\
\text { Technology (CJLT) }\end{array}$ & 2.053 & 2.071 & 2.374 & 2.008 & 1.943 & 1.871 \\
\hline $\begin{array}{l}\text { Computers and Composition Online } \\
(C C O)\end{array}$ & 2.075 & 2.250 & 2.625 & 1.500 & 2.000 & 2.000 \\
\hline Journal of Technology Education (JTE) & 2.081 & 1.867 & 2.567 & 2.222 & 1.875 & 1.875 \\
\hline $\begin{array}{l}\text { International Review of Research in } \\
\text { Open and Distr. Learning (IRRODL) }\end{array}$ & 2.082 & 2.017 & 2.354 & 1.981 & 1.960 & 2.098 \\
\hline $\begin{array}{l}\text { European Journal of Open and } \\
\text { Distance Learning (EURODL) }\end{array}$ & 2.105 & 2.090 & 2.470 & 2.040 & 1.930 & 1.993 \\
\hline $\begin{array}{l}\text { International Journal of Educational } \\
\text { Research and Technology (IJERT) }\end{array}$ & 2.109 & 1.900 & 2.563 & 1.875 & 2.083 & 2.125 \\
\hline $\begin{array}{l}\text { Asian Journal on Education and } \\
\text { Learning (AJEL) }\end{array}$ & 2.119 & 2.000 & 2.762 & 1.500 & 2.500 & 1.833 \\
\hline Journal of Distance Education (JDE) & 2.126 & 2.190 & 2.658 & 2.000 & 1.888 & 1.892 \\
\hline $\begin{array}{l}\text { Electronic Journal of e-Learning } \\
\text { (EJEL) }\end{array}$ & 2.141 & 2.303 & 2.463 & 2.088 & 1.833 & 2.017 \\
\hline $\begin{array}{l}\text { Turkish Online Journal of Educational } \\
\text { Technology (TOJET) }\end{array}$ & 2.147 & 2.000 & 2.400 & 2.100 & 2.083 & 2.150 \\
\hline $\begin{array}{l}\text { Contemporary Issues in Technology and } \\
\text { Teacher Education (CITE Journal) }\end{array}$ & 2.177 & 2.277 & 2.647 & 2.242 & 1.920 & 1.800 \\
\hline $\begin{array}{l}\text { Journal of Online Learning and } \\
\text { Teaching (JOLT) }\end{array}$ & 2.204 & 2.255 & 2.514 & 2.020 & 2.173 & 2.058 \\
\hline $\begin{array}{l}\text { Turkish Online Journal of Distance } \\
\text { Education (TOJDE) }\end{array}$ & 2.207 & 2.194 & 2.583 & 1.492 & 2.740 & 2.028 \\
\hline $\begin{array}{l}\text { THE Journal: Transforming Education } \\
\text { through Technology (THE Journal) }\end{array}$ & 2.230 & 2.400 & 2.673 & 1.800 & 1.875 & 2.400 \\
\hline
\end{tabular}


In Table 16, we show the mean scores for each characteristic (prestige, interaction, speed, RoA, and rigor) of a particular journal. The average score, which was calculated by getting an overall mean for each column in Table 15, signifies how, overall, participants rated each of the five factors among top 25 journals: prestige (2.164, range 1.197 to 2.400$)$, interaction (2.671, range 2.017 to 2.762 ), speed of review (2.00, range 1.197 to 2.333), rate of acceptance (2.037, range 1.625 to 2.740 ), and rigor of review process $(1.875,1.292$ to 2.400$)$. The statistic allows for comparison of the individual journal's mean of a certain factor with that of the total group. For example, one can see how Research in Learning Technology's prestige rating of 1.917 compares to the overall average of 2.164 . We did not calculate significant differences between individual journals. Instead, we sought to learn if the indicators had a correlation with the ranking of journals; in three cases, they did. Given the significance of the correlation of these indicators, it would appear that scholars' value of prestige, interaction, and rate of acceptance are useful determinants as to whether a particular journal is viewed as influential. Using Kendall's $\tau$-c to measure correlations, some significant correlations between the number of times a journal was selected among the top 5 (indicated by rank 1 in Table 16) are found. The correlation is negative because a lower mean score for a given characteristic signifies its higher value on the scale.

Table 16

Correlation statistics on characteristics

\begin{tabular}{lcccc}
\hline Characteristic & Overall mean & Top 25 mean & Kendall's $\tau$-c & $p$-value \\
\hline Prestige* & 2.164 & 2.05 & -2.424 & 0.015 \\
Interaction* & 2.671 & 2.46 & -3.155 & 0.002 \\
Speed of review & 2.001 & 1.96 & 0.271 & 0.786 \\
Rate of acceptance* & 2.037 & 1.94 & -3.562 & 0.000 \\
Rigor of editorial process & 1.875 & 1.89 & -0.407 & 0.684 \\
\hline
\end{tabular}

\section{Discussion}

Given the number of OAJs and the increased attention they have received, scholars tend to hold certain assumptions about these types of publications (Bohannon, 2013; Butler, 2013; Darley, Reynolds, \& Wickham, 2014; Lowenthal, 2015; Swan \& Brown, 2004). For instance, some assume that OAJs are inferior to subscription-based journals simply because they are open access, seemingly buying into an ideology of "something that costs nothing is worth nothing" (see Anderson, 2013; Zawacki-Richter et al., 2010). Others assume that those who publish in an OAJ do so because they were not able to publish in a traditional outlet. Still others assume that authors who publish in OAJs are making some type of socialjustice ideological claim about public access to scholarship. Due to these varying assumptions and the overall lack of guidance on how to identify high-quality versus low-quality OAJs, we set forth to explore academics' perceptions of OAJs. Our exploration resulted in a few interesting findings that address common assumptions like these. In the following section, we discuss key findings from our results and themes that emerge from them.

\section{Influential OAJs}

We began this study with the assumptions that high-quality OAJs exist, and that as OAJs continue to grow there might come a time when an academic decides to publish in an OAJ. However, the dramatic growth of new OAJs, coupled with the inherent biases many academics have towards OAJs and negative press about predatory journals, makes it very difficult for academics (especially graduate students and pre-tenured faculty) to separate respected OAJs from those that are either not respected or not known. Therefore, we set forth to ask academics, who actually had prior experience with OAJs, which OAJs they thought were most influential.

Our results suggest that there are in fact a number of educational technology (or related) OAJs that academics with OAJ experience both recognise and find influential. One observation that stands out about those OAJs identified as most influential: they are long-standing, well-known journals. In addition, three of the top 5 - Australasian Journal of Educational Technology, International Review of Research in Open and Distance Learning, and Educational Technology \& Society - are listed in the Journal Citation 
Reports and therefore have an ISI impact factor that compares favourably with long-standing subscription-based journals.

One finds some consensus with the top $20 \%$ of the OAJs, but after the top 15 , the list becomes varied; the number of votes for any particular journal title diminishes rather significantly. Also, both the PNAM group and the INTL group listed influential journals not listed by the other group, which suggests that the variability in perceptions of top journals is based in part on regional influences. From this, we observe that perceptions of influential or high-quality journals are contextual. For instance, our results show a relationship between geographic area(s) and the OAJs they find influential.

Our results also show a relationship between one's perceptions of an OAJ and whether or not the person has published in the journal. The rank of a journal, which was based on the total number of votes it received as among five most influential OAJs, (see Table 7) is significantly correlated with the respondents' experience with it $\left(\mathrm{r}^{\mathrm{c}}=3.94, p<.000\right)$. This essentially confirms what one could surmise, which is that any OAJ (and perhaps any journal) gets endorsed by those who have had some interaction with it (see Zawacki-Richter et al., 2010 for a related discussion). It must be kept in mind, however, that this statistic should not be applied to every individual case. One notable exception is one of the top ranked journals, EDUCAUSE Review. Though it is widely recognised by the participants, the vast majority of those listing it among their top 5 journals have had no direct experience with it (in full disclosure, we have both published with EDUCAUSE). Therefore, perceptions of journals (open or not) are likely influenced by geographic location and institutional culture, as well as a person's previous experience with the journal.

It is important to note that participants typically identified fewer than five influential OAJs (the average was four). This could add validity to the idea that participants were in fact differentiating between what they thought to be influential and non-influential journals. However, it could simply mean that they lack experience or knowledge of many of the other OAJs or that they in fact believe that approximately 70 of the other OAJs are not in fact influential. More research needs to be conducted to investigate what academics think of the educational technology (or related) OAJs they did not identify as influential.

\section{Important characteristics of OAJs}

With perfunctory knowledge of a web server and installation of free web applications, an OAJ can be started with little effort. Just as easily, though, an OAJ can be shuttered as its sponsors, institutional backers, or organisation leadership shift focus. Given both the growth and the volatility of OAJs, we wanted to explore what characteristics of OAJs academics find useful. The hope of exploring this was to help develop some guidelines to help academics evaluate OAJ quality.

In addition to being peer reviewed, our results suggest that influential OAJs are indexed, frequently cited by others, have a consistent publication record, and do not require publication fees. These important characteristics favour older OAJs that have had time to build a reputation as well as establish a consistent track record of issues and citations. Our results suggest that there are some differences between primarily North American (PNAM) academics and primarily international (INTL) academics. For instance, the INTL group listed the characteristic found in indexing/abstracting databases the most important (based on the mean response) characteristic of OAJs, whereas the PNAM group listed a consistent publication track record over time as the most important. Our analysis of the data shows a statistically significant difference in how participants in the INTL group rated the characteristic in the Social Science Citation Index compared to the PNAM group.

Between the groups' mean scores for the various characteristics listed in Table 9, a significant difference appears for abstracted and impact factor. That an OAJ is abstracted (information about the journal is collected via an abstracting service and then distributed through library databases) is significantly more important to the INTL group than for the PNAM group $(U=11463, p=.006)$. Just as important to the INTL group - significantly more so than to the PNAM group - is the impact factor for an OAJ $(U=$ $10893, p=.006$ ). The impact factor of a given journal is a ratio of "the number of cites in the current year to any items published in the journal in the previous two years" and "the number of substantive articles (source items) published in the same 2 years" (Garfield, 2005, p. 5). It is important to note that the 
number of citations counted is only to articles in journals that are indexed by the Social Science Citation Index (SSCI) (Smeyers \& Burbules, 2011), meaning that citations in books, chapters, and the plethora of non-indexed journals are not counted. Our results suggest that being indexed and having an impact factor is more important to the INTL group, data that supports anecdotes we have heard from international academics who report their institutional cultures as ones that very strongly emphasise publishing only in journals with such characteristics (also see Gisvold, 1999).

The impact factor, found in the SSCI, is the most common metric used to identify the quality of a journal, though Google Scholar's h-index is another that has become popular given that company's well-known search engine tools to quickly show where and how many times given articles are cited. As noted previously, impact factor itself has been problematised (Hecht et al., 1998, Smeyers \& Burbules, 2011). Furthermore, there are a number of shortcomings in relying solely on OAJs' impact factors as a sign of article quality. First, only four educational technology related OAJs have an SSCI impact factor. In Table 17, we list the journals found in Table 15, in alphabetical order, along with both the impact factor metric and Google Scholar's hr-index, which is "h5-index is the h-index for articles published in the last 5 complete years. It is the largest number $\mathrm{h}$ such that $\mathrm{h}$ articles published in 2010-2014 have at least $\mathrm{h}$ citations each" (GoogleScholar, n.d., ๆ 4). It is not a credible assertion that the only quality OAJ articles are found in such a small number of outlets. Also, one must understand that impact factor focuses on journals themselves and not the articles (Smeyers \& Burbules, 2011). Finally, one should question a purely quantitative analysis of what "impact" means (West \& Rich, 2012). Although one might see that a journal has had a significant number of articles cited over time, the question for any article (in an OAJ or other) is if it adds significant value in terms of practice or theory building. As an analogy, many readily recognise brand names of fast-food restaurants and the total economic impact is measured in billions of dollars, but nutritional and medical studies make very clear that another significant impact exists, and this is not at all positive.

Table 17

Impact factor and h5-index numbers for top OAJ from Table 15

\begin{tabular}{|c|c|c|}
\hline Journal & $\begin{array}{l}\text { 5-year } \\
\text { impact factor }\end{array}$ & h5-index \\
\hline Asian Journal on Education and Learning (AJEL) & -- & -- \\
\hline Australasian Journal of Educational Technology (AJET) & 1.01 & 33 \\
\hline Canadian Journal of Learning and Technology (CJLT) & -- & 13 \\
\hline Computers and Composition Online (CCO) & -- & -- \\
\hline $\begin{array}{l}\text { Contemporary Issues in Technology and Teacher Education (CITE } \\
\text { Journal) }\end{array}$ & -- & 12 \\
\hline Educational Technology \& Society (ETS) & 1.38 & 40 \\
\hline EDUCAUSE Quarterly / Review (EDUCAUSE) & -- & -- \\
\hline eLearning Papers (eL Papers) & -- & -- \\
\hline Electronic Journal of e-Learning (EJEL) & -- & 16 \\
\hline European Journal of Open and Distance Learning (EURODL) & -- & -- \\
\hline First Monday & -- & 31 \\
\hline International Journal of Designs for Learning (IJDL) & -- & -- \\
\hline $\begin{array}{l}\text { International Journal of Educational Research and Technology } \\
\text { (IJERT) }\end{array}$ & -- & -- \\
\hline $\begin{array}{l}\text { International Review of Research in Open and Distr. Learning } \\
\text { (IRRODL) }\end{array}$ & 1.00 & 36 \\
\hline Journal of Asynchronous Learning Networks (JALN) & -- & 19 \\
\hline Journal of Computer-Mediated Communication (JCMC) & 3.80 & 32 \\
\hline Journal of Distance Education (JDE) & -- & -- \\
\hline Journal of Online Learning and Teaching (JOLT) & -- & 20 \\
\hline
\end{tabular}




\begin{tabular}{lcc}
\hline Journal of Technology Education (JTE) & -- & -- \\
Kairos & -- & -- \\
Online Journal of Distance Learning Administration (OJDLA) & -- & -- \\
Research in Learning Technology (ALT-J) & -- & 20 \\
THE Journal: Transforming Education through Technology (THE & -- & -- \\
Journal) & -- & 10 \\
Turkish Online Journal of Distance Education (TOJDE) & $--*$ & 26 \\
Turkish Online Journal of Educational Technology (TOJET) & - \\
\hline
\end{tabular}

* TOJET has an impact factor (.956) for 2011, but a 5-year impact factor as not yet been established.

\section{Orientation towards and experiences with OAJs}

With few exceptions OAJs are still a relatively new phenomenon and, as such, many academics are at various places on the continuum of investigating their perceived attributes (Rogers, 2003). Therefore we set out to find out what those who have OAJ experience actually think of them. Contrary to common assumptions about authors' motivation to publish in OAJs (e.g., commitment to social justice issues or review processes), our results suggest that academics publish in OAJs primarily based on the content of their manuscript. In other words, while about $22 \%$ of respondents reported that an OAJ is usually their first choice, almost $70 \%$ stated that it depended on the content. This suggests that the majority of academics appear to be more pragmatic than ideological when deciding where to publish their work. They also appear to be happy with their experience with OAJs. Approximately two-thirds of all respondents characterised their review experience as "consistently excellent" or "consistently good." Furthermore, $71 \%$ of participants indicated that they would definitely, or were very highly likely, to publish in an OAJ within the next 18 months.

We must make clear that the OAJs recognised as influential can be ranked in various ways. From one perspective, a tally of votes creates a list that one is tempted to associate with a quality rating. This democratic process, though, does not mean that the top group necessarily is associated with quality. When we asked participants to give input about key characteristics for each OAJ they listed as influential, a rather different ranking emerges. In Table 15 we present the top 5 as ranked by their total average score of five characteristics. What results are some fairly dramatic shifts in ranking. For example, though Research in Learning Technology (ALT-J) does not appear high up in the Table 7 list, it appears first in Table 15. The highest ranked journal (in terms of votes) in the first listing, EDUCAUSE, falls 10 places on the Table 15 list. This comparison of ranks makes clear that academics (or publishers) who try to assert that a given publication is "highly influential" cannot do so without a very clear description of the factors that make it so. We offer our own list (below) that attempts to account for total votes and mean scores with the belief that the list represents a defensible ranking of OAJs in educational technology, at least with respect to the data gathered in this study.

\section{Prestige of OAJs}

Electronic journals began to emerge in the early days of the Internet, with many academics sceptical of electronic publications for a number of reasons (Anderson \& McConkey, 2009) - seemingly legitimate at the time - that have now proved to be misplaced. The evolution into a digital culture in academe brought with it different expectations and, now, scholars rather take for granted publishers' digital services (e.g., pre-publication releases, indexing). Despite the ubiquity of such web-based services, a sentiment still exists (just as it does with online education) that electronic OAJs are inferior to those that require a subscription. To learn more about academics' perceptions of educational technology (or related) OAJs, we specifically asked participants about how prestigious their selected influential journals were compared to other top journals in our field. More than half reported that they viewed them as prestigious, which is not too surprising. Interestingly, though, $23 \%$ of our participants listed them as less prestigious, with another $10 \%$ reporting that they preferred not to answer the question. Thus, even among those with OAJ experience and who specifically chose certain OAJs, nearly $35 \%$ did not indicate that the OAJs selected as influential have the same prestige as other (traditional) journals in their field. 


\section{Regional differences}

The differences we saw in the top 5 list among groups of participants is in some ways even more starkly contrasted in questions about the perceived importance of selected journal characteristics. As has been stated, we consistently found that participants in the INTL group felt more strongly about the necessity of an impact factor and abstracting/indexing for any journal, including OAJs. These differences likely arise from different academic or institutional cultures in various regions of the world (Gisvold, 1999; Shao \& Scherlen, 2007). Indeed, even among US institutions, there are marked differences in academic cultures, with research-intensive universities placing a good deal more emphasis on a faculty member's ability to publish certain types of articles in certain journals and teaching-intensive universities emphasising pedagogical excellence (Shin \& Cummings, 2010). When it comes to using the INTL versus PNAM data to better understand perceptions of OAJs, we believe that there are at least three pertinent points and two important questions.

First, although one does find overlap among a certain subset of OAJs in terms of which ones are the most influential, one must keep in mind that any given journal's significance has a regional component. Second, at least at the moment, whether a journal is open or not is less important to the INTL group of scholars than quality marks (e.g., ISI impact factor) that are applied to all journals. Third, participants in the PNAM group are seemingly less concerned about things like impact factor for any type of journal, including OAJs. One interpretation of the second and third observation is that no matter the differences in preferences, the INTL and PNAM groups are consistent in their expectations for a publication outlet.

Two questions arise from the data comparing the regional groups. One important question has to do with the impact of what a SSCI listing means for the future of new journals. If OAJs continue to proliferate, how will new journals in educational technology build any credibility among scholars outside of North America? Will it be the case that articles appearing in such journals are xenocentric given the reluctance of international scholars to publish in them? Another question that arises from our comparison of INTL and PNAM groups is the participants' actual knowledge of how journals, particularly OAJs, operate. Do the authors truly understand the logistical aspects of a journal (such as review speed, or peer review processes in general) that are assumed to be characteristics of quality? As has been noted, impact factor is a metric that is problematic (Elliott, 2014; Gisvold, 1999). Are there other factors beyond traditional metrics and what we have explored to help journals achieve respect among scholars? Exploring these questions would indeed make for interesting studies in the future.

\section{Limitations}

More than 300 academics participated in our survey, and we are confident that the data gathered offers a useful, interesting perspective on OAJs in educational technology. Yet, despite the care we took to craft the instrument, solicit participants, collect data, and so on, we understand the limitations of our study. One limitation, of course, is the limited response when one considers the sheer number of authors who are publishing articles in OAJs. Future studies should work to increase the overall number so as to increase statistical validity. Additionally, for this report, we reported only the results of scholars with OAJ experience. This was not at all done to discount the voices of those without such experience, but because our original intent was to learn what those with OAJ experience thought. Future studies should perhaps focus on the feedback of both groups and compare and contrast the attitudes, perceptions, or experiences of the groups. Finally, as we learned, OAJs are not something unique to North America scholarship; we were fortunate to get the input of scholars from around the world. However, our survey was in English only, so we are here presenting data only of those who are proficient in it. Those who plan future research should collaborate with bilingual peers in order to make instruments available in languages other than English.

\section{Conclusion and recommendations}

Based on data gathered, we present below what we have determined to be the top 25 OAJs in educational technology. We urge scholars to use it simply as a peer-informed guide to help guide their own research, as a resource about where to start looking for credible open access scholarship in our field, and as a 
means for those outside educational technology to understand how academics in it differentiate among the myriad of OAJ choices. We do not endorse the use of our list for marketing purposes; please note that the list appears in alphabetical order, not in ranked order. Information about these journals, based on our research and other available metrics, also appears on the EdTech Journals site at http://edtechjournals.org.

- Australasian Journal of Educational Technology

- Canadian Journal of Learning and Technology

- Contemporary Issues in Technology and Teacher Education

- Educational Technology \& Society

- EDUCAUSE Review

- eLearning Papers

- Electronic Journal of e-Learning

- European Journal of Open and Distance Learning

- First Monday

- IEEE Transactions on Learning Technologies*

- International Journal of Artificial Intelligence in Education*

- International Journal of Designs for Learning

- International Journal of Educational Research and Technology

- International Review of Research in Open and Distance Learning

- Journal of Asynchronous Learning Networks

- Journal of Computer-Mediated Communication

- Journal of Distance Education

- Journal of Information Technology Education

- Journal of Online Learning and Teaching

- Journal of Technology Education

- Kairos

- Online Journal of Distance Learning Administration

- $\quad$ Research in Learning Technology (ALT-J)

- Turkish Journal of Educational Technology

- Turkish Online Journal of Distance Education

* The journal did not appear in the top 25 rankings from our survey, but is noted here because it has other metrics indicating that it is highly regarded.

\section{Recommendations}

Our recommendations, based on our findings and insights from others writing about publishing and publications, are intended first and foremost for faculty members. We also believe that administrators of departments where educational or instructional technology is taught should consider the ramifications for policy around journal acceptability given that faculty members are very often rated based on the perceived quality of the outlets in which they publish. First, the presence or absence of an OAJ on any given list, even one built on empirical evidence such as ours, is not an indication of the quality of a particular article. What matters less is how a journal rates and instead how a particular article has been cited (Smeyers \& Burbules, 2011). The question thus becomes whether or not a given outlet, open access or subscription-based, has the potential to distribute an article so that it achieves as much influence as possible - in terms of availability, indexing, archiving, and so on.

With respect to OAJs, one might look at our top 25 list to see which ones are more likely to be read than others. At the institutional level, a list such as the one we provide above may help tenure and promotion committees understand what professionals in our field think of a particular journal's overall quality, regardless of formal metrics like impact factor, h-index, or others. Other factors, such as found in Table 9, might be used to justify the inclusion of any journal on a list that gets developed. 
There are circumstances beyond an author's control that affect the availability or access to certain OAJs. Examples during the past few years include the shuttering of Innovate, a slight change to words within the IRRODL acronym ("distance" became "distributed"), the combining of EDUCAUSE Review and EDUCAUSE Quarterly, and the recent name change of the Journal of Asynchronous Learning Networks to Online Learning Journal and its subsequent merger with the Journal of Online Learning and Teaching. Changes to names, formats, and so on have an obvious implication for accessing and archiving scholars' work. In such cases, it is important for professionals to vigorously discuss the changes so that others might be fully informed of the ramifications. It is important for others outside a given field to not see OAJs merely as glorified weblogs that can be created and revised on a whim, but as outlets that are responsive to the needs and goals of the academic community.

Finally, the OAJs found on our list, at least at the time of publication, are both free to access and do not pass along costs to contributing authors. An increasing number of established publishers allow authors to pay to make an article open access (e.g., sometimes up to US\$3,000). However those fees are justified based on costs, the outlets that charge for publishing are poorly received by colleagues in our field, as shown by our research. The overwhelming consensus is that the spirit of open access is promulgated best not only when a journal's content is freely accessible, but also when contributions to a journal are freely received and published. Thus, should a charge for publication be incurred, it behooves the faculty member to fully describe the cost and justification for it.

\section{References}

Agrawal, A. A. (2014). Four more reasons to be skeptical of open-access publishing. Trends in Plant Science, 19(3), 133. doi:10.1016/j.tplants.2014.01.005

Anderson, T. (2013). Open access scholarly publications as OER. The International Review of Research in Open and Distributed Learning, 14(2), 81-95. doi:10.1007/s11192-008-0217-x

Anderson, T., \& McConkey, B. (2009). Development of disruptive open access journals. Canadian Journal of Higher Education, 39(3), 71-87. Retrieved from http://ojs.library.ubc.ca/index.php/cjhe/article/view/477

Bohannon, J. (2013). Who's afraid of peer review? Science, 342(6154), 60-55. doi:10.1126/science.342.6154.60

Björk, B. C., Welling, P., Laakso, M., Majlender, P., Hedlund, T., \& Guðnason, G. (2010). Open access to the scientific journal literature: Situation 2009. PloS One, 5(6), e11273. doi:10.1371/journal.pone.0011273

Butler, D. (2013, March 27). The dark side of publishing. Nature, 499, 433-435. doi:10.1038/495433a

Contreras, A., \& Golin, G. (2009). The real and the fake: Degree and diploma mills. Change: The Magazine of Higher Learning, 41(2), 36-43. doi:10.3200/CHNG.41.2.36-43

Craig, I. D., Plume, A. M., McVeigh, M. E., Pringle, J., \& Amin, M. (2007). Do open access articles have greater citation impact?: A critical review of the literature. Journal of Informetrics, 1(3), 239-248. doi:10.1016/j.joi.2007.04.001

Darley, R. J., Reynolds, J., \& Wickham, C. (2014). Open access journals in humanities and social science. London: British Academy for the Humanities and Social Sciences.

Davis, P. (2009, June 10). Open access publisher accepts nonsense manuscript for dollars [Blog post]. The Scholarly Kitchen. Retrieved from http://scholarlykitchen.sspnet.org/2009/06/10/nonsense-fordollars/

Davis, P. M. (2011). Open access, readership, citations: A randomized controlled trial of scientific journal publishing. The FASEB Journal, 25(7), 2129-2134. doi:10.1096/fj.11-183988 fj.11-183988

EdTech Journals. (n.d.). Retrieved July 15, 2015, from http://edtechjournals.org

Elliott, D. B. (2014). The impact factor: A useful indicator of journal quality or fatally flawed? Ophthalmic \& Physiological Optics, 34(1), 4-7. doi:10.1111/opo.12107

Feltman, R. (2014, November 24). Shoddy scientific journal accepts paper titled "Get me off your $\mathrm{f}^{* *}$ king mailing list". Washington Post. Retrieved from http://www.washingtonpost.com/news/speaking-of-science/wp/2014/11/24/shoddy-scientific-journalaccepts-paper-titled-get-me-off-your-fking-mailing-list/

Feltman, R. (2014, December 8). Two scientific journals accepted a study by Maggie Simpson and Edna Krabappel. Washington Post. Retrieved from http://www.washingtonpost.com/news/speaking-of- 
science/wp/2014/12/08/two-scientific-journals-accepted-a-study-by-maggie-simpson-and-ednakrabappel/

Frass, W., Cross, J., \& Gardner, V. (2014). Open access survey. London: Taylor \& Francis \& Routledge. Retrieved from http://www.tandf.co.uk/journals/explore/open-access-survey-june2014.pdf

Garfield, E. (2005, September). The agony and the ecstasy: The history and meaning of the journal impact factor. Paper presented at the International Congress on Peer Review and Biomedical Publication, Chicago, Illinois. Retrieved from http://garfield.library.upenn.edu/papers/jifchicago2005.pdf

Gisvold, S. (1999). Citation analysis and journal impact factors: Is the tail wagging the dog? Acta Anaesthesiologica Scandinavica, 43(10), 971-973. doi:10.1034/j.1399-6576.1999.431001.x

GoogleScholar. (n.d.) Google scholar metrics. Retrieved August 5, 2015, from https://scholar.google.com/intl/en-us/scholar/metrics.html\#metrics

Hecht, F., Hecht, B., \& Sandberg, A. A. (1998). The journal "Impact Factor": A misnamed, misleading, misused measure. Cancer Genetics and Cytogenetics, 104(2), 77-81. doi:10.1016/S01654608(97)00459-7

Hensley-Clancy, M. (2014, November 13). How a disgraced college chain trapped its students in poverty. BuzzFeed News. Retrieved from http://www.buzzfeed.com/mollyhensleyclancy/lowereducation\#.cyrrykAmVW

Khabsa, M., \& Giles, C. L. (2014). The number of scholarly documents on the public web. PLoS ONE 9(5), e93949. doi:10.1371/journal.pone.0093949

Laasko, M., Welling, P., Bukvova, H., Nyman, L., Björk, B.-C., \& Hedlund, T. (2011). The development of open access journal publishing from 1993 to 2009. Plos One, 6(6): e20961. doi:10.1371/journal.pone.0020961

Lewis, D. W. (2012). The inevitability of open access. College \& Research Libraries, 73(5), $493-506$. doi:10.5860/crl-299

Lowenthal, P. R. (2015). Open-access journals in educational technology. In J. M. Spector (Ed.), Encyclopedia of educational technology (pp. 554-556). Thousand Oaks, CA: Sage.

Meszaros, J. (2014, September 9). For profit colleges: Maintaining a permanent underclass. The Huffington Post. Retrieved from http://www.huffingtonpost.com/julia-meszaros/for-profit-collegesmaint_b_5788466.html

Noorden, R.V. (2013, March 27). Open access: The true cost of science publishing. Nature, 495, 426429. doi:10.1038/495426a

Oliver, M. (2012). The risk of open scholarship: Avoiding irony in the promotion of technology for scholarly communications. Educational Technology, 52(6), 22-25. Retrieved from ERIC database. (EJ1000546)

Rich, P. J., \& West, R. E. (2012). New technologies, new approaches to evaluating academic productivity. Educational Technology, 52(6), 10-14. Retrieved from ERIC database. (EJ1000543)

Ritzhaupt, A. D., Sessums, C. D., \& Johnson, M. C. (2012). Where should educational technologists publish their research? An examination of peer-reviewed journals within the field of educational technology and factors influencing publishing. Educational Technology, 52(6), 47-56.

Rogers, E. M. (2003). Diffusion of innovations (5th ed.). New York, NY: Free Press.

Shao, X., \& Scherlen, A. (2007). Perceptions of open access publishing among academic journal editors in China. Serials Review, 33(2), 114-121. doi:10.1016/j.serrev.2007.02.002

Shin, J. C., \& Cummings, W. K. (2010). Multilevel analysis of academic publishing across disciplines: research preference, collaboration, and time on research. Scientometrics, 85(2), 581-594. doi:10.1007/s11192-010-0236-2

Smeyers, P., \& Burbules, N. (2011). How to improve your impact factor: Questioning the quantification of academic quality. Journal of Philosophy of Education, 45(1), 1-17. doi:10.1111/j.14679752.2011.00787.x

Stromberg, J. (2014, February 24). A reporter published a fake study to expose how terrible some scientific journals are. Vox. Retrieved from http://www.vox.com/2014/4/24/5647106/a-reporterpublished-a-fake-study-to-expose-how-terrible-some

Swan, A., \& Brown, S. (2004). Authors and open access publishing. Learned Publishing, 17(3), $219-224$. doi:10.1087/095315104323159649

Togia, A., \& Tsigilis, N. (2006). Impact factor and education journals: A critical examination and analysis. International Journal of Educational Research, 45(6), 362-379. doi:10.1016/j.ijer.2007.02.001 
Van Noorden R. (2013). Open access: The true cost of science publishing. Nature, 495(7442), 426-429. doi: $10.1038 / 495426$ a

Veletsianos, G., \& Kimmons, R. (2012). Assumptions and challenges of open scholarship. The International Review of Research In Open and Distance Learning, 13(4), 166-189. Retrieved from http://www.irrodl.org/index.php/irrodl/article/view/1313/2304

West, R. E., \& Rich, P. J. (2012). Rigor, impact and prestige: A proposed framework for evaluating scholarly publications. Innovative Higher Education, 37(5), 359-371. doi:10.1007/s10755-012-92143

Worlock, K. (2004). The pros and cons of open access. Nature. doi:10.3163/1536-5050.99.3.008

Zawacki-Richter, O., Anderson, T., \& Tuncay, N. (2010). The growing impact of open access distance education journals: A bibliometric analysis. International Journal of E-Learning \& Distance Education, 24(3). Retrieved from http://ijede.ca/index.php/jde/article/view/661

Corresponding author: Ross A. Perkins, rossperkins@,boisestate.edu

Australasian Journal of Educational Technology (c) 2016.

Please cite as: Perkins, R.A., \& Lowenthal, P.R. (2016). Open access journals in educational technology: Results of a survey of experienced users. Australasian Journal of Educational Technology, 32(3), 1837. 